\title{
Nurse practitioners: Developing the next generation of health care leaders through an internship program
}

\author{
Nicole Twine, Nicole Fontenot, Meagan Sam \\ Houston Methodist Hospital, Houston, Texas, United States
}

Received: June 27, 2017

Accepted: August 30, 2017

Online Published: December 18, 2017

DOI: $10.5430 /$ jnep.v8n5p13

URL: https://doi.org/10.5430/jnep.v8n5p13

\begin{abstract}
The current health care environment demands competent providers who possess advanced knowledge and skills necessary to care for an increasingly acute patient population. Nurse Practitioners (NPs) are uniquely positioned to meet the challenges of today's health care climate because they blend their ability to treat illness with a strong emphasis on patient safety and outcomes while providing patient- and family-centered care. The role of the NP requires sophisticated clinical and critical thinking skills that foster the ability to synthesize theoretical, scientific, and contemporary clinical knowledge for the assessment and management of both healthy and illness states. It is crucial that NPs possess advanced skills to provide safe and effective patient care outcomes. The literature suggests that there is a transition period after graduation for novice NPs. Developing additional focused educational opportunities to supplement the training phase of their graduate education can better prepare student NPs and consequently enhance this transition phase. As a result, newly licensed NPs can deliver high-quality, safe patient care sooner after obtaining their advanced practice license. At a time when health care reform is rapidly evolving, it is critical that NPs are reliable, competent professionals. Houston Methodist Hospital created an employment-based educational opportunity for elite graduate NP students: Leading Education and Advancing Professionals (LEAP). This 12-month program is a structured evidence-based internship program that incorporates didactic training, clinical rotations, and simulation. Students are provided hands-on training that features interdisciplinary and collaborative care model components from experienced Houston Methodist NPs. The goal is to help develop the next generation of health care providers in which the expectation is to lead and not follow in meeting today's health care challenges. The aim of this article is to present an overview of the LEAP program.
\end{abstract}

Key Words: Nurse practitioners, Program development, Simulation, Advanced practice nurse, Internship

\section{INTRODUCTION}

In the current health care environment, demand is high for competent providers who possess the advanced knowledge and skills necessary to care for an increasingly acute patient population. Nurse Practitioners (NPs) are uniquely positioned to meet the challenges of today's health care. NPs blend their ability to treat illness with a strong emphasis on patient safety and outcomes while providing patient- and family-centered care. NPs are crucial for accomplishing The
Triple Aim. Developed by the Institute for Healthcare Improvement, The Triple Aim describes a specific approach to optimizing health system performance. The 3 aims are to improve the quality of care, improve the health of populations, and lower health care cost. NPs are uniquely positioned to meet these demands, because they blend the abilities to treat illness with a strong emphasis on patient safety and care of the whole person. For this to be accomplished, their education should rapidly evolve to prepare newly licensed NPs

\footnotetext{
*Correspondence: Nicole Twine; Email: nltwine2@HoustonMethodist.org; Address: Houston Methodist Hospital 6565 Fannin St., Houston, Texas,
} United States. 
to fill the health care gap sooner upon completion of their training. The lack of internship experiences, however, could extend the time it takes for NPs to be fully prepared to meet their patients' needs. ${ }^{[1]}$

The role of the NP requires sophisticated clinical and critical thinking skills that give NPs the ability to synthesize theoretical, scientific, and contemporary clinical knowledge for the assessment and management of both healthy and illness states. ${ }^{[2]}$ It is crucial that NPs possess advanced skills to provide safe and effective patient care outcomes. ${ }^{[3]}$ There is an adjustment period after graduation for novice NPs. Ineffective adjustment in professional identity can impact self-confidence, impair development of the new role, and influence decisions to remain in the job and in the profession within the first year of clinical practice for new NPs. ${ }^{[4]}$ Thus, additional focused educational opportunities to supplement the training phase of their graduate education have been established to better prepare student NPs and consequently enhance this transition phase so that newly licensed NPs can deliver high-quality, safe patient care sooner after obtaining their advanced practice license. At a time when health care is rapidly evolving, it is critical that NPs are reliable, competent professionals. Houston Methodist Hospital has created an employment-based educational opportunity for elite graduate NP students called Leading Education and Advancing Professionals (LEAP). This 12-month program is a structured evidence-based internship that incorporates didactic training, clinical rotations, and simulation. Students are provided hands-on training that features interdisciplinary and collaborative care model components from experienced Houston Methodist NPs. The goal is to help develop the next generation of health care providers in which the expectation is to lead and not follow in meeting today's health care challenges.

\section{BACKGROUND}

The Acute Care Nurse Practitioner (ACNP) role evolved to fill the health care gaps created by changes in resident education in the early 1990s. Since that time, the number of ACNPs has grown to approximately $17,000 .{ }^{[5]}$ These practitioners deliver $62 \%$ of their care in the hospital setting. ${ }^{[6]}$ Currently, the curriculum in many ACNP programs does not provide specialized training in any particular specialty area; rather, the focus is on acute processes across the lifespan. Specialty training has been delegated to professional organizations after graduation. For these reasons, several hospital systems have begun designing their own postgraduate residency programs for NPs new to a particular specialty, such as trauma, critical care, or cardiology. In addition to needing specialty training, transitioning from a registered nurse to a NP can be challenging personally and professionally. Although the availability of postgraduate training programs is expanding, there is an unmet need for graduate internships. Much of the ACNP postgraduate training is geared toward on-the-job training in which the ACNP is self-taught, which frequently results in disparities between what is expected and what the ACNP is capable of delivering. ${ }^{[7]}$ This can lead to suboptimal development in communication, assessment, and critical thinking skills that may delay the NP's ability to advance to the level of proficiency needed to ensure safe patient outcomes. Ineffective transition to practice can cause a lack of development of clinical competence, role dissatisfaction, and ineffective utilization of health care resources that might have been used to deliver quality health care.

An increasing concern in nursing in recent years is the ability of nurses to keep pace with the rapid changes in health care. NPs must maintain a high level of vigilance. The NP must be able to synthesize theoretical, scientific, and contemporary clinical knowledge to assess and manage both healthy and illness states. ${ }^{[1]}$ It is crucial that NPs possesses skills that provide them with expertise in assessment, communication, and critical thinking, which are integral to safe and effective patient care outcomes. ${ }^{[8]}$ Although NP students are taught these essential concepts and skills in school, they do not always get to fully synthesize these into their gestalt. Bays et al. ${ }^{[9]}$ found that training physicians and nurse practitioners via small-group simulations showed "significant improvement in trainees' ability to communicate bad news and express empathy." NP students exposed to challenging patient care situations, both in actual clinical situations as well as in a simulation lab, will get many opportunities to develop their critical thinking skills. Simulated patient experiences allow students to receive somewhat individualized attention and feedback and allow faculty additional opportunities to observe a student's critical thinking skills. ${ }^{[10]}$ The ultimate goal is to increase the clinician's ability to save a hospitalized patient's life when there is an unexpected complication that may be a condition not present on admission. ${ }^{[11]}$ The proficient NP must be able to perform a comprehensive health assessment, which is a "systematic, deliberative and interactive process by which nurses use critical thinking to collect, validate, analyze and synthesize the collected information in order to make judgments about the health status and life processes of individuals". ${ }^{[12]}$ The inclusion of simulation experiences offers an additional educational advantage for learning how to recognize and treat acute and complex clinical problems. ${ }^{[13]}$ It has been suggested that high-fidelity patient simulation is a valuable learning strategy for promoting critical thinking and clinical decision-making skills. ${ }^{[14]}$ Internship programs offer graduate students the opportunity 
to gain more practical experience and more exposure to real practice situations, which will give them an opportunity to utilize skills they are already developing in their traditional educational programs. The inclusion of simulation experiences will offer an additional educational advantage for learning how to recognize and treat acute and complex clinical problems. ${ }^{[13]}$

The transition from student to professional NP is an important and difficult adjustment to make, and the presence and quality of an internship program can affect the length of time needed for effective entry into practice. Several researchers have determined that there is an actual transition period that new graduates undergo as they enter into NP practice. ${ }^{[15]}$ The new role as an NP is one in which there is more autonomy and advanced decision-making. Learning environments that support critical thinking and synthesis of information are known to facilitate role transition. ${ }^{[16]}$ Obtaining effective and quality education to function in the NP role is the first stage in the transition from a student NP to an employed NP. For example, Heitz et al. ${ }^{[16]}$ revealed that the RN-to-FNP (family nurse practitioner) role transition occurs in 2 phases. Phase I occurs during the educational process. Phase II is the role transition from graduate FNP to independent FNP. This occurs during the first 6 months to 2 years after graduation. ${ }^{[16]}$ In another study about NP graduates discussing the adequacy of their education preparation, Jones et al. ${ }^{[3]}$ found a need for more educational content and clinical experiences specific to the care of older adults.

The Houston Methodist Hospital LEAP program was developed to give NP students an opportunity to develop stronger assessment, communication, and critical thinking skills. The average NP program requires 500 to 600 clinical hours before entry into practice. This additional exposure to clinical training increases the opportunity for NP students to transition into practice sooner. The purpose of this article was to describe the development of the NP internship.

\section{LEAP PROGRAM DEVELOPMENT}

\subsection{Gap analysis}

Before designing the LEAP program, the NP Service leadership conducted a gap analysis to evaluate the missed learning needs of recently graduated NPs. They found that while their recent graduates had an appropriate understanding of disease processes and disease management, they lacked experience in applying that knowledge in real-world situations. Additionally, they lacked confidence in their clinical skills. The LEAP program was designed to meet these needs and to ease the transition into NP practice.

Published by Sciedu Press

\subsection{Curriculum design}

The LEAP program was designed to be a 12-month program that offers NP students the opportunity to obtain handson training that features interdisciplinary and collaborative model components from experienced Houston Methodist NPs. The program is designed around 4 education components:

- Didactic lectures

- Simulation

- Clinical rotations

- Professional development

The curriculum is not intended to replicate or replace NP programs; instead, it was designed to enhance and augment what the LEAP students are learning in their NP programs and assist in their transition into NP practice.

\subsubsection{Didactic lectures}

The LEAP students attend a 4-hour lecture each month. Each lecture is designed to address common issues newly licensed NPs face as they transition into practice. The topics vary each month between professional development topics and disease management topics. The clinical topics are intended to be practical and problem-based, utilizing case scenarios and real-world examples, so that the LEAP students can work through common clinical problems they are likely to see. The professional development topics discuss implementing evidence-based practice, understanding how to impact organizational priorities, quality and safety, mindfulness, and imposter syndrome, among others. See Figure 1 for a full description of all topics covered in the LEAP curriculum.

Each lecture is developed and presented by experts in that area. Many of the clinical topics are presented by the NP Service NPs. Other experts from the organization also participate, such as nurse researchers, nurse educators, and executive leaders. These guest lecturers are selected on the basis of their expertise but also to demonstrate to the LEAP students the potential impact nurses and advance practice nurses can have on a health care organization.

\subsubsection{Simulation}

Simulation has been shown to be a viable method of training advance practice nurses. For the LEAP program, simulation is incorporated into the curriculum to enhance the didactic lectures, to evaluate the LEAP students' ability to remain calm under pressure, and to give them the opportunity to take on a bedside leader role in a safe environment. Each simulation scenario is designed to start with a relatively stable patient, allowing the LEAP student time to assess the situation, perform a physical exam, and manage a stable patient. Then the patient deteriorates and eventually goes into cardiac 
arrest. The LEAP student is expected to manage the change in condition and function as the team leader in an advanced cardiac life support scenario.

\begin{tabular}{|c|c|}
\hline \multicolumn{2}{|c|}{ LEAP Didactic Lectures } \\
\hline Month & Lecture Topics \\
\hline January & $\begin{array}{l}\text { LEAP Student Orientation } \\
\text { Simulation \#1 }\end{array}$ \\
\hline February & $\begin{array}{l}\text { Chest Pain } \\
\text { Patient Evaluation } \\
\text { Fever } \\
\text { Clinical Documentation }\end{array}$ \\
\hline March & $\begin{array}{l}\text { 12-Lead Electrocardiograph Workshop } \\
\text { Acute Abdominal Pain } \\
\text { Chest X-Ray Interpretation } \\
\text { NP Impact on Outcomes }\end{array}$ \\
\hline April & $\begin{array}{l}\text { Shock } \\
\text { Quality \& Safety } \\
\text { Evidence-Based Practice } \\
\text { Now you are an NP...What Next? }\end{array}$ \\
\hline May & Simulation \#2 \\
\hline June & $\begin{array}{l}\text { Shortness of Breath } \\
\text { Antifungals } \\
\text { Fluid Overload }\end{array}$ \\
\hline July & $\begin{array}{l}\text { Wound Care } \\
\text { Antibiotics } \\
\text { Altered Mental Status } \\
\text { Mindfulness and Conscious Breathing }\end{array}$ \\
\hline August & $\begin{array}{l}\text { Tachycardia } \\
\text { Hypertension } \\
\text { Hypoxia } \\
\text { Imposter Phenomenon }\end{array}$ \\
\hline September & Simulation \#3 \\
\hline October & $\begin{array}{l}\text { Arterial Blood Gas Interpretation } \\
\text { Role of Case Management and Social Work } \\
\text { Transitions of Care } \\
\text { Syncope }\end{array}$ \\
\hline November & $\begin{array}{l}\text { Palliative Care } \\
\text { Dehydration } \\
\text { Magnet Update }\end{array}$ \\
\hline December & Simulation \#4 \\
\hline
\end{tabular}

Figure 1. LEAP didactic lectures

To make the simulation more realistic, the scenarios are designed to be chaotic and full of distractions. Actors are utilized to portray nurses, physicians, and family members. These actors give clues to the LEAP student to help them, but can also distract the students. These distractions include disruptive family members, physicians who say they will be there to help but never arrive, and nurses who do not implement the LEAP student's orders. Often the simulator operator will cause the manikin to deteriorate if the LEAP student is paying more attention to the distractions than to the simulated patient.

After each simulation experience, the LEAP student, actors, and simulator operator debrief the scenario. The LEAP student is given a chance to discuss concepts they missed with the educator and how it felt being the team leader.

\subsubsection{Clinical rotations}

The LEAP students rotate through various specialties including cardiovascular surgery, medicine, cardiology, the emergency response team, and neurosurgery. Figure 2 is an example of a full clinical rotation schedule. Each LEAP student is paired with a preceptor during their clinical rotation to provide continuity throughout that rotation. The LEAP student rounds on their patients, writes progress notes, and discusses the plan of care with the interdisciplinary team. After consultation, LEAP students place verbal orders on behalf of the preceptor.

Because the LEAP students are employees and registered nurses, they are able to do more than traditional students can during clinical rotations. This allows them to gain more real-world experiences.

Initially the plan was to have the LEAP students spend the bulk of their time with the emergency response team, who respond to all rapid responses and cardiac arrests and manage patients who screen positive for sepsis. When the gap analysis was initially completed, it was felt that the students would benefit the most from extensive exposure to emergencies and changing-patient-condition events. However, after the first few months, it became apparent that the LEAP students needed, and desired, a wider range of clinical experiences; rotations were thus added in many more clinical settings.

\subsubsection{Professional development}

Each LEAP student must participate in several professional development activities. First, they must complete an evidence-based practice project. These projects focus on improving patient care and advancing the nursing profession. After their first couple of months, the students identify an area of need from their clinical rotations. Then they develop an evidence-based recommendation for practice change. The LEAP students then present their projects during a poster presentation that is open to all hospital staff. Because of the restrictions on time, the projects are not implemented; however, the LEAP students are encouraged to choose projects that they could implement once they graduate and transition into their NP practice.

The LEAP students also get the opportunity to attend scholarly conferences. The NP Service hosts Fundamentals of Critical Care Support, and each LEAP student gets to attend during their time in the program. Additionally, the students can attend any conference that the NP Service hosts for free. These conferences include topics such as gerontology, sepsis, and the annual NP/PA Action STAT Bootcamp. These events offer continuing education units, while creating exposure to professional activities that the NP Service expects from their NPs. 


\begin{tabular}{|c|c|c|c|c|c|}
\hline \multicolumn{6}{|c|}{ LEAP Student Clinical Rotations } \\
\hline Month & Student 1 & Student 2 & Student 3 & Student 4 & Student 5 \\
\hline Aug 2015 & Orientation & Orientation & Orientation & Orientation & Orientation \\
\hline Sep 2015 & Cardiology & $\begin{array}{l}\text { Cardiovascular } \\
\text { Surgery }\end{array}$ & Medicine & $\begin{array}{l}\text { Cardiovascular } \\
\text { Surgery }\end{array}$ & Observation \\
\hline Oct 2015 & $\begin{array}{l}\text { Cardiovascular } \\
\text { Surgery }\end{array}$ & Medicine & Cardiology & Neurosurgery & Oncology \\
\hline Nov 2015 & Heart Failure Clinic & Observation & $\begin{array}{l}\text { Cardiovascular } \\
\text { Surgery }\end{array}$ & Cardiology & $\begin{array}{l}\text { Cardiovascular } \\
\text { Surgery }\end{array}$ \\
\hline Dec 2015 & Observation & Neurosurgery & Medicine & Rehab & Cardiology \\
\hline Jan 2016 & Rehab & Cardiology & Neurosurgery & Observation & $\begin{array}{l}\text { Emergency } \\
\text { Response Team }\end{array}$ \\
\hline Feb 2016 & Cardiology & $\begin{array}{l}\text { Emergency } \\
\text { Response Team }\end{array}$ & $\begin{array}{l}\text { Cardiovascular } \\
\text { Surgery }\end{array}$ & Heart Failure Clinic & Neurosurgery \\
\hline Mar 2016 & $\begin{array}{l}\text { Emergency } \\
\text { Response Team }\end{array}$ & Rehab & Observation & $\begin{array}{l}\text { Emergency } \\
\text { Response Team }\end{array}$ & Rehab \\
\hline Apr 2016 & Neurosurgery & Cardiology & Rehab & CV Surgery & Heart Failure Clinic \\
\hline May 2016 & CV Surgery & Observation & $\begin{array}{l}\text { Emergency } \\
\text { Response Team }\end{array}$ & Medicine & Cardiology \\
\hline Jun 2016 & Medicine & $\begin{array}{l}\text { Emergency } \\
\text { Response Team }\end{array}$ & Heart Failure Clinic & Cardiology & CV Surgery \\
\hline Jul 2016 & Heart Failure Clinic & CV Surgery & Cardiology & $\begin{array}{l}\text { Emergency } \\
\text { Response Team }\end{array}$ & Observation \\
\hline Aug 2016 & Observation & Medicine & CV Surgery & Observation & $\begin{array}{l}\text { Emergency } \\
\text { Response Team }\end{array}$ \\
\hline
\end{tabular}

Figure 2. Sample clinical rotation calendar

Lastly, the LEAP students are required to present at grand rounds and at a quarterly morbidity and mortality $(\mathrm{M} \&$ $\mathrm{M})$ meeting. These 2 meetings allow the LEAP students to develop presentations, share their clinical knowledge, and practice presenting in front of their peers. The students get to work together to develop the presentations and are supported by the LEAP program curriculum director to develop high-quality work.

\subsection{Student requirements and application process}

When designing the LEAP program, the NP Service leadership wanted to create a rigorous application process that Published by Sciedu Press mirrored that of other internship and residency programs in health care. This process includes an application, a personal statement, and multiple panel interviews. Figure 3 discusses the application components.

Students applying for the LEAP program must currently be enrolled in an accredited Adult/Gerontology Acute Care Nurse Practitioner (AG-ACNP) Program and have a grade point average of at least 3.5 on a 4.0 scale. The applicant must also have completed core NP graduate classes, including pharmacology, pathophysiology, and health assessment. Complete applicant qualifications are contained in Figure 4. 


\section{LEAP Student Packet Components}

1. A professional curriculum vitae $(\mathrm{CV})$ or resume

2. Transcript

3. Three (3) satisfactory academic/professional references (Peer, Nursing Manager, and Faculty)

4. Personal statement reflecting interests and career goals

5. Copies of ACLS and BLS certification

Figure 3. LEAP student packet components

\section{LEAP Student Applicant Qualifications}

Minimum of 2 years of current clinical nursing experience.

Completed a minimum of 2 semesters of graduate program.

Completed Advanced Pharmacology, Advanced Pathophysiology, and Advanced Physical Exam/Health Assessment courses.

Must graduate at the end of the 12-month calendar year.

Must be able to work 12 hours per week.

Figure 4. LEAP student applicant qualifications

Applications are accepted twice per year for admittance to the program in the spring and in the fall. Once the application period ends, the NP Service leadership reviews all applicants and selects the most qualified applicants for in-person interviews. Student applicants are interviewed by the program director, the program educator, and a panel of NPs. Students are selected based on interview feedback and the quality of their application. For the first cohort, 5 student applicants were selected. Subsequent cohorts have increased in size with the fifth cohort having 13 students.

LEAP students participating in the program are paid employees and are required to work at least one shift per week. They are "per diem" PRN Students NPs. If the student is already a Houston Methodist Hospital employee, the NP Service leadership team coordinates with the leadership of the home department so that the one shift per week requirement can be achieved.

\section{OUTCOMES}

Houston Methodist has had great success with the LEAP program since its inception. Fourteen students have graduated from the LEAP program in the past 2 years. Houston Methodist Hospital has retained 13 (93\%) of the students who participated in the LEAP program and the NP Service has retained $7(50 \%)$ students. The students participating in the LEAP program become well acclimated to the environment and culture of Houston Methodist Hospital and the NP Service during their stint with the program. Spending so much time with the hospital and NP Service aids the students in making more informed decisions when selecting places of employment. In addition to the distinct clinical experience students gain while working in the LEAP program, students learn integral operational processes including how to effectively use the electronic medical record and documentation system.

Another important outcome to the LEAP program has been reducing the cost of orientation. New graduate NPs receive 12 weeks of orientation, which costs $\$ 25,000$ per newly graduated NP. The LEAP students retained by the NP Service have not needed to undergo a traditional 12-week orientation, which has eliminated those expenses. Additionally, the LEAP students hired by the NP Service have stayed longer than other newly graduated NPs hired by the program. Since their transition from LEAP student to NP, 85\% (12/14) of the retained LEAP students are still with the NP Service. Compared to other newly graduated NPs hired into the NP Service during that same time period, $63 \%$ have left for employment elsewhere. Hiring LEAP students into the NP Service has enabled the department not only to reduce the cost of orientation but also to retain the students hired, thus reducing the cost of hiring and training new staff.

\section{DiscuSSION}

The LEAP program created a supportive but rigorous training environment for NP students to develop into their new role through clinical rotations, assigned preceptors, didactic lectures, simulation scenarios, and professional development during the 12-month period. Students were required to present a case study at NP Grand Rounds, present at M \& $\mathrm{Ms}$, and complete an evidence-based practice project.

In the first year, 5 students completed the program. Four of the 5 students were retained at $\mathrm{HMH}$ after graduation. The students were asked for feedback on how the program could be improved. Although this was an additional time commitment along with their graduate studies and jobs, each student expressed that the opportunity to work in an NP role for a year prior to graduation was significant for their confidence level. Although the students were required to complete 500 to 600 clinical hours for their graduate programs, being in LEAP afforded them an additional 650 hours, which gave them more time to master skills, learn to work with a multidisciplinary team as a provider, and have a better understanding of the roles and expectation of an advance practice 
provider at a large organization.

Opportunities for ongoing improvement and continual development of the program were identified by the students and preceptors. The program has expanded to accept FNP students and Psych NP students. The clinical rotation schedules were developed and based on core competencies for each specialty NP. There has been an addition of more clinical rotations from critical care to ED to outpatient opportunities. Feedback from preceptors has been used in ongoing development and expansion of the program. Clinical objectives for each rotation were redefined. A process was created to provide a handoff from one preceptor to the next so as to not duplicate additional training and to continue to expand on the knowledge the student had gained.

\section{Conclusion}

The LEAP program was developed to give graduate students additional time and exposure to develop and hone new skills that would prepare them much sooner to provide safe and effective quality patient care outcomes. ${ }^{[8]}$ While NP students are taught essential concepts and skills in school, they do not always get to fully synthesize these into their gestalt before they are practicing NPs. A large gap exists between what is expected in practice and what the NP can deliver without formal residency training. Creating an additional focused educational opportunity during the training phase of graduate education has been shown to increase clinical confidence and make the transition to the NP role much easier. The literature has shown that proper transition to advanced practice nursing is fundamental to improved patient outcomes. A future study will be conducted to identify the transitional experience of the NPs that participated in the LEAP program, with a goal of identifying information that will be used to further develop educational programs for NPs.

\section{Conflicts of InTEREST Disclosure}

The authors declare that there is no conflict of interest.

\section{REFERENCES}

[1] Hain D, Fleck L. Barriers to nurse practitioner practice that impact healthcare redesign. Online J Issues Nurs. 2014; 19(2).

[2] Stanley JM, Crabtree MK, editors. Adult-gerontology acute care nurse practitioner competencies [Internet]. American Association of Colleges of Nurses. 2012 [cited 2017 Mar 28]. Available from: http://www.aacn.nche.edu/geriatric-nursing/Adu lt-Gero-ACNP-Competencies.pdf

[3] Jones J, Kotthoff-Burrell E, Kasss-Wolff J, et al. Nurse practitioner graduates 'Speak out' about the adequacy of their educational preparation to care for older adults: a qualitative study. J Am Assoc Nurse Pract. 2015; 27(2): 689-706. https://doi.org/10.1002/2327 $-6924.12230$

[4] Bush CT. Postgraduate nurse practitioner training: what nurse executives need to know? J Nurs Adm. 2014; 44(12): 625-7. PMid:25393137 https://doi.org/10.1097/NNA. 0000000000 000138

[5] NP Facts [Internet]. American Association of Nurse Practitioners. 2016 [cited 2017 Mar 29]. Available from: http://www . aanp. org /images/documents/about-nps/npfacts . pdf

[6] Kleinpell R, Goolsby M. American Academy of Nurse Practitioner National Nurse Practitioner Sample Survey: focus on acute care. J Am Acad Nurse Pract. 2006; 18: 393-4. PMid:16958768 https://doi.org/10.1111/j.1745-7599.2006.00154.x

[7] Harris C. Bridging the gap between acute care nurse practitioner education and practice: the need for postgraduate residency programs. J Nurse Pract. 2014 May; 10(5): 331-6. https ://doi.org/10.101 6/j.nurpra.2014.03.003
[8] Jones M. Developing clinically savvy nursing students: an evaluation of problem-based learning in an associate degree program. Nurs Educ Perspect. 2008; 29(5): 278-83. PMid: 18834057

[9] Bays AM, Engelberg RA, Back AL, et al. Interprofessional communication skills training for serious illness: evaluation of a small-group, simulated patient intervention. J Palliat Med. 2014; 17(2): 156-66. PMid:24180700 https : //doi .org/10.1089/jpm. 2013.0318

[10] Pittman OA. The use of simulation with advanced practice nursing students. J Am Acad Nurse Pract. 2012; 24(9): 516-20. PMid:22931476 https://doi.org/10.1111/j.1745-7599.20 $12.00760 . \mathrm{x}$

[11] Needleman J, Buerhaus PI. Failure-to-rescue: comparing definitions to measure quality of care. Med Care. 2007; 45(10): 913-5. PMid:17890986 https://doi.org/10.1097/MLR.0b013e3181 $58 \mathrm{bf} 10$

[12] Haidar E. ANP's: assessing \& prescribing. Journal of Community Nursing [serial online]. July 2008; 22(7): 10-13.

[13] Corbridge SJ, McLaughlin R, Tiffen J, et al. Using simulation to enhance knowledge and confidence. Nurse Pract. 2008; 33(6): 12-3. PMid: 18528196

[14] Aronson BS, Squires TE. Patient simulation enhances students' critical thinking skills. Nursing Spectrum Online [Internet]. [cited 2017 Mar 29]. Available from: http://www. include.nurse.com/ap ps/pbcs.dll/article?AID $=2004410040332$

[15] Brown M, Olshansky E. From limbo to legitimacy: a theoretical model of the transition to the primary care nurse practitioner role. Nurs Res. 1997; 46(1): 46-51. PMid:9024424 https://doi.org/ 10.1097/00006199-199701000-00008

[16] Heitz LJ, Steiner SH, Burman ME. RN to FNP: a qualitative study of role transition. J Nurs Educ. 2004; 43(9): 416-420. PMid:15478695 